\title{
NÍVEL DE SATISFAÇÃO DOS USUÁRIOS DO SETOR DE CIÊNCIAS AGRÁRIAS E DE TECNOLOGIA EM RELAÇÃO À BIBLIOTECA DO CAMPUS DE UVARANAS DA UNIVERSIDADE ESTADUAL DE PONTA GROSSA
}

\author{
LEVEL OF SATISFACTION OF USERS OF THE \\ AGRICULTURAL SCIENCE AND TECHNOLOGY SECTOR \\ CONCERNING THE LIBRARY AT THE UVARANAS \\ CAMPUS OF THE PONTA GROSSA STATE UNIVERSITY
}

\author{
Wilson Padilha de Oliveira ${ }^{1}$ \\ Maria Luzia Fernandes Bertholino
}

\begin{abstract}
RESUMO
Este trabalho identificou o nível de satisfação de $10 \%$ dos usuários reais, da área de Ciências Agrárias e de Tecnologias da Universidade Estadual de Ponta Grossa, com o objetivo de levantar a percepção dos mesmos em relação à qualidade percebida nos serviços oferecidos pela Biblioteca do Campus de Uvaranas. Foram avaliadas as variáveis: espaço físico, atendimento, acervo e servidores sob a visão das categorias: alunos de graduação, professores e servidores, representados por 90 sujeitos. O instrumento utilizado na metodologia foi a entrevista com seleção dos sujeitos aleatória. A partir disso, pode-se identificar algumas oportunidades para a Biblioteca qualificar seus serviços e satisfazer as necessidades de seus usuários, e as conclusões desta análise poderão orientar possíveis ações futuras.
\end{abstract}

Palavras-chave: Usuários. Nível de satisfação. Biblioteca Universitária.

\begin{abstract}
This study identified the level of satisfaction of $10 \%$ of actual users of the Agricultural Science and Technology sector at the Ponta Grossa State University in order to know about their perception in relation to the quality of the services offered by the library of the Uvaranas Campus. The variables: physical space, service, collections and staff were analyzed by undergraduate students, teachers and workers represented by 90 subjects. The selection of the subjects interviewed followed a random procedure. The study identified the aspects that need improvement so that the library has more quality and its services meet the needs of their users. The conclusions of this analysis can be used as guidelines for future actions.
\end{abstract}

Keywords: Users. Satisfaction level. University Library.

\footnotetext{
${ }^{1}$ Graduado em Teologia pela Faculdade de Teologia Batista do Paraná, Especialista em Gestão Pública pela Universidade Estadual de Ponta Grossa. E-mail: <wpoliveira@uepg.br>

2Graduada em Biblioteconomia pela Universidade Estadual de Londrina, Mestre em Ciência da Informação pela Pontifícia Universidade Católica de Campinas e bibliotecária da Universidade Estadual de Ponta Grossa. E-mail: <mluzia@uepg.br>.
} 


\section{Introdução}

As bibliotecas universitárias, como órgãos de apoio ao ensino, à pesquisa e a extensão, estruturam seus recursos e serviços buscando a satisfação de seus usuários. Estabelecem em suas missões atuar como mediadoras entre a informação e a comunidade universitária, promovendo a sua interação com o universo dos materiais bibliográficos existentes à disposição.

Portanto, realizar estudos que busquem identificar o nível de satisfação dos mesmos torna-se importante para obter um feedback e avaliar se vem atendendo e suprindo suas reais necessidades e verificando se suas metas estão sendo atingidas.

Deve-se considerar também o nível de eficiência de seus serviços que, segundo Lancaster (1996), estabelece quão bem os serviços satisfazem à demanda.

Conhecer o nível de satisfação dos usuários pode indicar os fatores que estão influenciando positiva ou negativamente o andamento dos serviços da biblioteca, afinal as bibliotecas universitárias, desde os mais remotos tempos, desempenham papel importante na função de preservar e disseminar conhecimento onde um elemento importante é o bom atendimento, o que promoverá um conceito alto para a mesma. Também é indispensável que todos os funcionários conheçam bem os setores, pois na falta de algum funcionário, não ficará prejudicado o seu funcionamento, afirma Prado (2003).

Conforme destaca Schweitezer (2007) as bibliotecas são distribuidoras de informação, desempenhando papel fundamental no desenvolvimento da sociedade, ocasionando transformações científicas, tecnológicas e educacionais em diversas áreas do conhecimento.

Assim, gerenciar uma biblioteca não serve apenas para mudar ou estabelecer o papel da mesma, mas sim para promover uma ampla discussão entre bibliotecários e usuários, com o objetivo principal de estabelecer uma nova relação entre os mesmos, com propósitos claros, definidos a partir das necessidades reais de cada grupo.

A partir de uma nova filosofia, voltada para a apresentação de serviços com alto nível de qualidade, evitando-se o retrabalho e o desperdício e indo ao encontro dos interesses, desejos e necessidades dos usuários, é possível definir procedimentos para um atendimento adequado.
O gerenciamento dos recursos, e principalmente do capital humano em bibliotecas ou centros de informação de sucesso, exige por parte dos responsáveis em cargos de direção, postura de líder - o líder sábio - é esse o perfil profissional do terceiro milênio, um líder com valores éticos, que seja respeitado e que saiba respeitar a equipe, liderando mais pelo exemplo de que pela ameaça de punição (OLIVEIRA, 2000).

Em relação ao Bibliotecário observa-se uma nova atitude deve ser adotada no sentido de oferecer aos clientes serviços com qualidade, rapidez e atualidade, sendo para isso necessário investir no treinamento de recursos humanos e, assim, estabelecer uma nova cultura no ambiente de trabalho (RAMOS, 1999).

A adoção da filosofia da qualidade torna-se necessária para uma gestão mais eficaz das bibliotecas e para garantir a sua sobrevivência diante das exigências cada vez maiores dos usuários, que tem a facilidade de comparar diferentes unidades e serviços de informação mediante o uso das tecnologias de informação disponíveis.

Para Penniman (1993 citado por LANCASTER (1994, p. 10):

Precisamos planejar uma mudança na nossa orientação, de guardiães dos livros para guias através do universo do conhecimento. [...] A habilidade dos bibliotecários de serem criativos, e de se moverem para fora da biblioteca, e para dentro de papéis mais amplos da informação, nos dará a medida do bibliotecário do futuro.

$\mathrm{Na}$ sociedade do conhecimento, mais do que um intermediador entre a informação e o usuário, o bibliotecário será um refinador de informação, assim contribuindo para a redução do tempo do usuário na recuperação da mesma, pois a mais utilizada tecnologia - Internet - possibilita o acesso a bilhões de informações, e o especialista da informação conhece os melhores caminhos para obter maior eficácia na busca. (OLIVEIRA, 2000).

Ao abordar uma discussão sobre o Moderno Profissional da Informação (MIP), Mason (1990 citado por GUIMARÃES. 1998, p. 21) caracteriza esse profissional como "aquele que é capaz de fornecer a informação certa, da fonte certa, ao cliente certo, no momento certo, da forma certa, e um custo que justifique seu uso." 
Para atingir de fato suas finalidades e responder às reais necessidades de sua clientela, a biblioteca precisa estar preparada administrativa e tecnicamente, ter sua missão, propósitos e objetivos bem definidos, dispor de um bom acervo bibliográfico, ampliando pela possibilidade de acesso remoto na obtenção da informação, contar com pessoal capacitado e em número suficiente, dispor de equipamentos e materiais necessários (RAMOS, 1999).

Em relação aos usuários a primeira vez que se ouviu falar da relação usuário-bibliotecário registrada pela literatura data de 1876, na Conferência histórica de bibliotecários, Samuel Swett Green, da Worcester Free Library apresentou sua preocupação em estabelecer comunicação pessoal (ROTHSTEIN, 1995). Tal preocupação vem evoluindo ao longo do tempo até os dias de hoje, nos quais o usuário passa a ser visto como cliente.

Diversos estudos vêm sendo realizado buscando analisar métodos e satisfação dos usuários.

Pinheiro e Godoy (2002) analisando qualidade em serviços e a satisfação dos usuários em Bibliotecas Universitárias estabelecem o objetivo de conhecer a realidade vivenciada no interior dessas bibliotecas a fim de agregar conhecimentos que contribuam no aperfeiçoamento das atividades executadas e na flexibilização e organização interna do gerenciamento da informação. Investiga o grau de satisfação e insatisfação em relação aos seguintes indicadores: atendimento, serviços, acervo bibliográfico e condições físicas das bibliotecas. Concluem que para apresentar um serviço de qualidade, precisa-se de quadro de funcionários treinados, comprometidos, motivados, com boa remuneração e ferramentas de trabalho atualizada e adequadas às atividades de trabalho.

Outro estudo interessante é de Baptista e Cunha (2007) que aborda a trajetória histórica de estudo de usuários, a partir da década de 1960, comentando as fases quantitativas e qualitativas com as vantagens e desvantagens dos principais métodos e coleta de dados. Os autores concluem que as metodologias devem ser usadas de acordo com o tipo de pesquisa a ser desenvolvida e que não é a metodologia que determina a pesquisa e sim o problema que se pretende resolver.

Baptista e Leonardt (2011) apresentam uma pesquisa de satisfação de usuários, com o objetivo de levantar a percepção dos usuários em relação à qualidade percebida nos serviços oferecidos pela Biblioteca da Universidade de Caxias do Sul. Os resultados dão subsídios para a Instituição qualificar seus serviços e satisfazer seus usuários em ações futuras.

O estudo de Silveira et al. (2012) analisa a satisfação e perfil do usuário buscando obter um melhor perfil dos alunos da Instituição e suas impressões sobre o acervo e serviços oferecidos.

\section{Material e métodos}

O universo desta pesquisa foi constituído de usuários da Biblioteca do Campus de Uvaranas do Setor de Ciências Agrárias e de Tecnologia, composto por 906 inscritos, sendo 836 alunos de graduação, 8 funcionários e 62 professores. A amostra foi fixada em $10 \%$ deste universo, representada por 90 usuários.

O instrumento de coleta de dados foi a entrevista estruturada composta de perguntas fechadas que buscaram identificar os índices de satisfação dentro de cinco níveis de intensidade: totalmente insatisfeito, insatisfeito, satisfeito, totalmente satisfeito e não sei, cujo instrumento foi baseado no trabalho de Baptista e Leonardt (2011).

A seleção dos usuários para entrevista foi aleatória e a tabulação dos dados obedeceu à sequência das questões da entrevista.

\section{Resultados e discussão}

\section{Categorias de Usuários}

As categorias contempladas neste estudo foram alunos de graduação, professores e servidores discriminados conforme tabela 1.

Tabela 1 - Categoria de Usuários do Setor de Ciências Agrárias e de Tecnologia da Biblioteca do Campus de Uvaranas

\begin{tabular}{l|c|c|c|c}
\hline & \multicolumn{2}{|c|}{$\begin{array}{c}\text { BIBLIOTECA CAMPUS } \\
\text { DE UVARANAS }\end{array}$} & \multicolumn{2}{|c}{ TOTAL } \\
\hline CATEGORIA & $\mathrm{n}^{\text {o }}$ & $\%$ & $\mathrm{n}^{\circ}$ & \multicolumn{1}{c}{$\%$} \\
\hline Professores & 06 & 10 & 62 & 6,84 \\
Alunos de Graduação & 83 & 10 & 836 & 92,27 \\
Servidores & 01 & 10 & 08 & 0,88 \\
\hline Total & 90 & 10 & 906 & 100 \\
\hline
\end{tabular}

Fonte: $\mathrm{O}$ autor. 
Quanto à categoria de usuários, foi constatado que a maioria, $836(92,27 \%)$, eram alunos de graduação; 62 (6,84\%), professores; $8(0,88 \%)$, funcionários.

\section{Espaço Físico da Biblioteca}

Para análise do espaço físico da Biblioteca foram investigadas três variáveis: adequação dos espaços, estrutura geral e salas de estudos.

O grau de satisfação dos usuários dos segmentos estudados estão demonstrados nos gráficos 1 a 3 .
A adequação do espaço físico e a estrutura geral foram consideradas satisfatórias para $69 \%$ dos alunos respondentes, apresentando percentuais quase proporcionais, de $18 \%$ e $20 \%$, para a insatisfação em relação à essas variáveis. A variável sala de estudos apresentou um maior percentual dividido em opiniões que variaram entre insatisfeito $(43 \%)$ e satisfeito $(33 \%)$, destacando-se ainda $12 \%$ de alunos que encontram-se totalmente insatisfeitos com sala de estudos do ambiente físico da Biblioteca.

Gráfico 1 - Espaço Físico da Biblioteca - grau de satisfação dos alunos de graduação

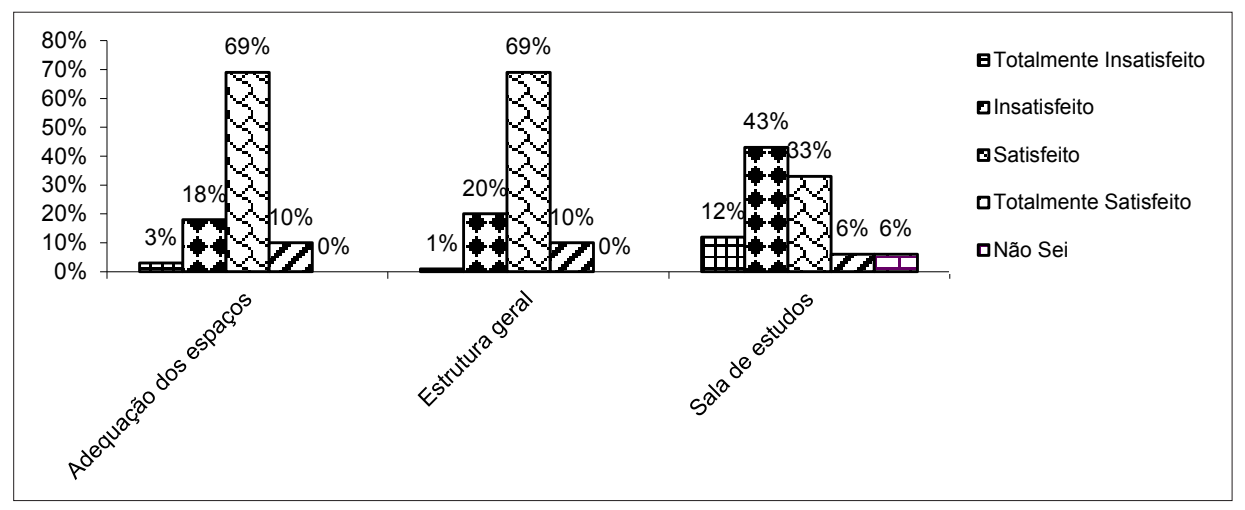

Gráfico 2 - Espaço Físico da Biblioteca - grau de satisfação dos professores

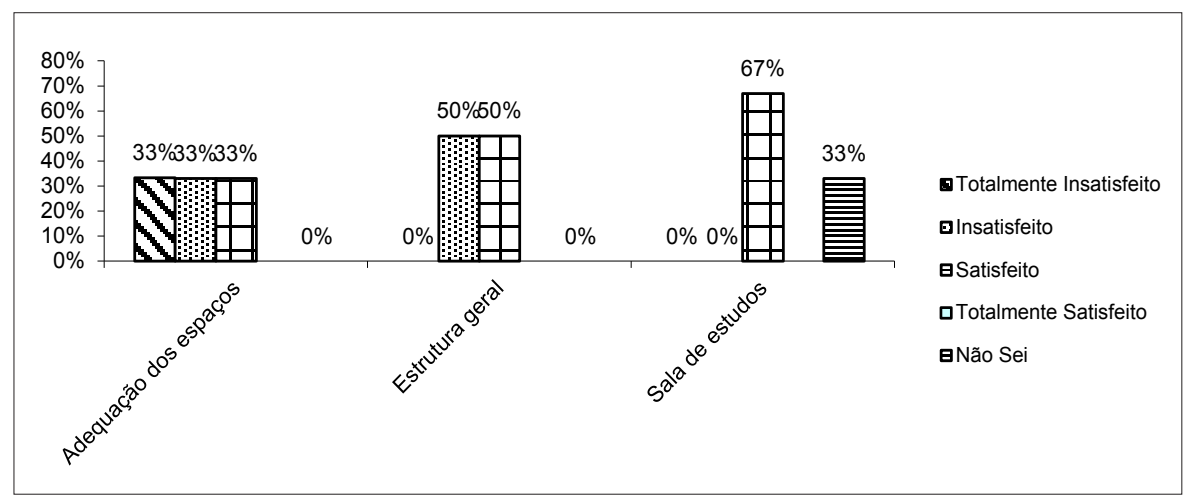

Para a categoria professores o item adequação dos espaços divide as opiniões em proporções iguais (33\%) entre os níveis de totalmente satisfeito a satisfeito. A estrutura geral divide a opinião também em percentuais idênticos $(50 \%)$ entre os níveis satisfeito e insatisfeito e em relação às salas de estudo para $67 \%$ que demonstram satisfação $33 \%$ não sabem estabelecer um nível de satisfação. 
Gráfico 3 - Espaço Físico da Biblioteca - grau de satisfação dos servidores

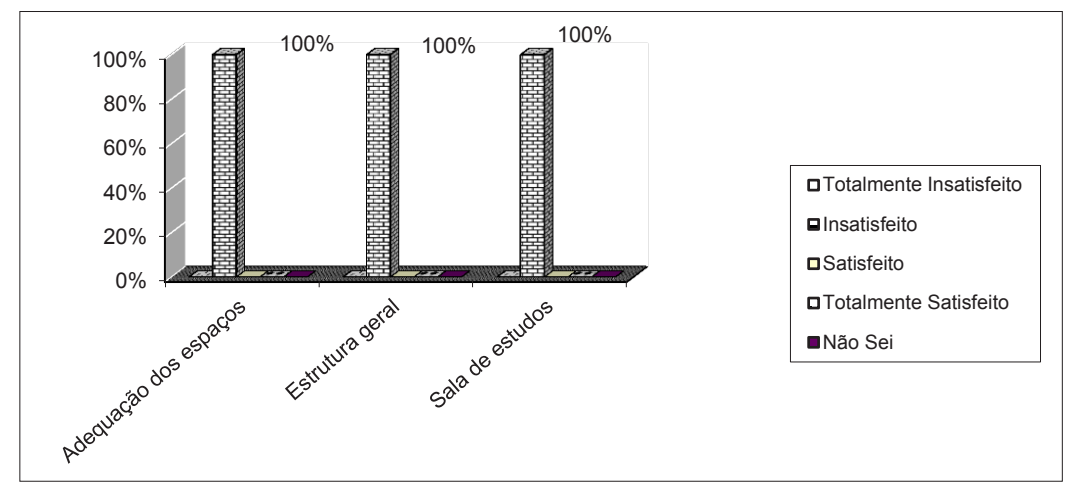

Unanimamente a categoria de servidores encontra-se insatisfeita em relação ao espaço físico da Biblioteca nas variáveis analisadas.

\section{Atendimento da Biblioteca}

Para análise do atendimento da Biblioteca foram consideradas as seguintes variáveis: rapidez, serviços da Internet, serviços de recepção, serviços de empréstimos, horário de atendimento e divulgação de informações.

O grau de satisfação dos usuários dos segmentos estudados estão demonstrados nos gráfi$\cos 4$ a 6 .

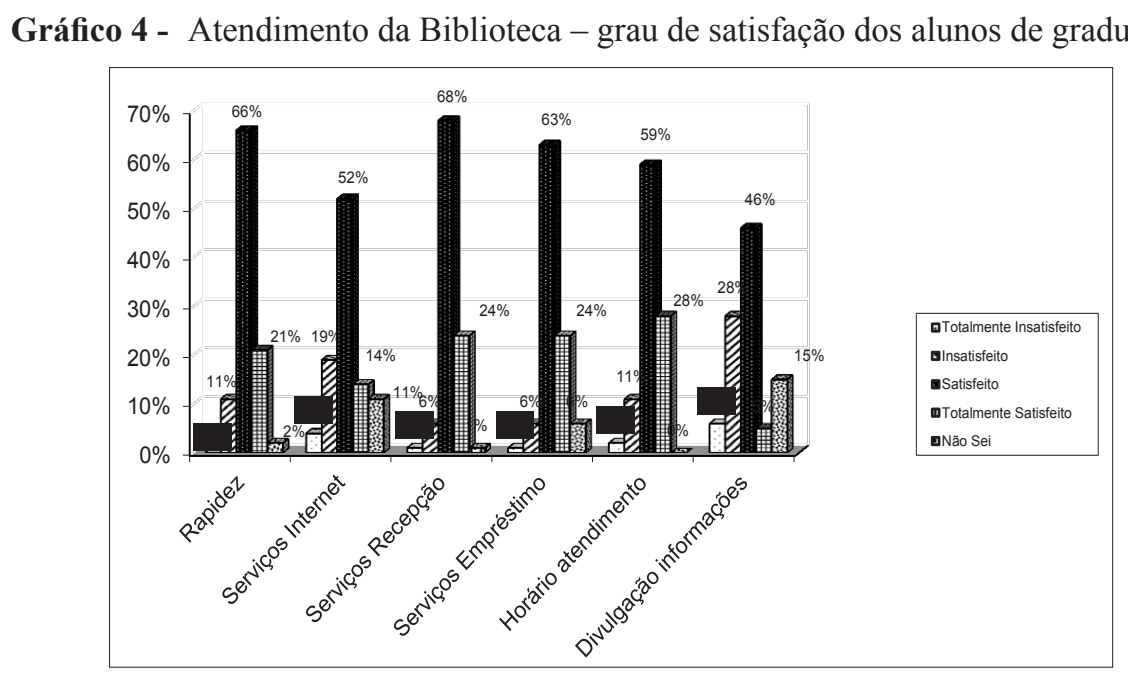

A maioria dos alunos de graduação, indicaram o nível satisfeito para as variáveis analisadas em percentuais que variaram de $68 \%$ a $46 \%$. Destacando-se maior satisfação com serviços de recepção, rapidez e serviços de empréstimo e em menor percentual para divulgação de informações. O nível de insatisfação foi indicado em percentuais que variaram de $28 \%$ a $11 \%$, principalmente para divulgação de informações e serviços da internet. O ní- vel de totalmente satisfeito obteve uma distribuição percentual que variou de $28 \%$ a $14 \%$, destacando-se principalmente horário de atendimento, serviços de empréstimo, serviços de recepção, rapidez e um menor percentual para serviços internet.

Os dados obtidos demonstram uma proporcionalidade próxima entre os níveis de satisfação, porém deve-se observar que todos os níveis obtiveram algum índice percentual. 
Gráfico 5 - Atendimento da Biblioteca - grau de satisfação dos professores

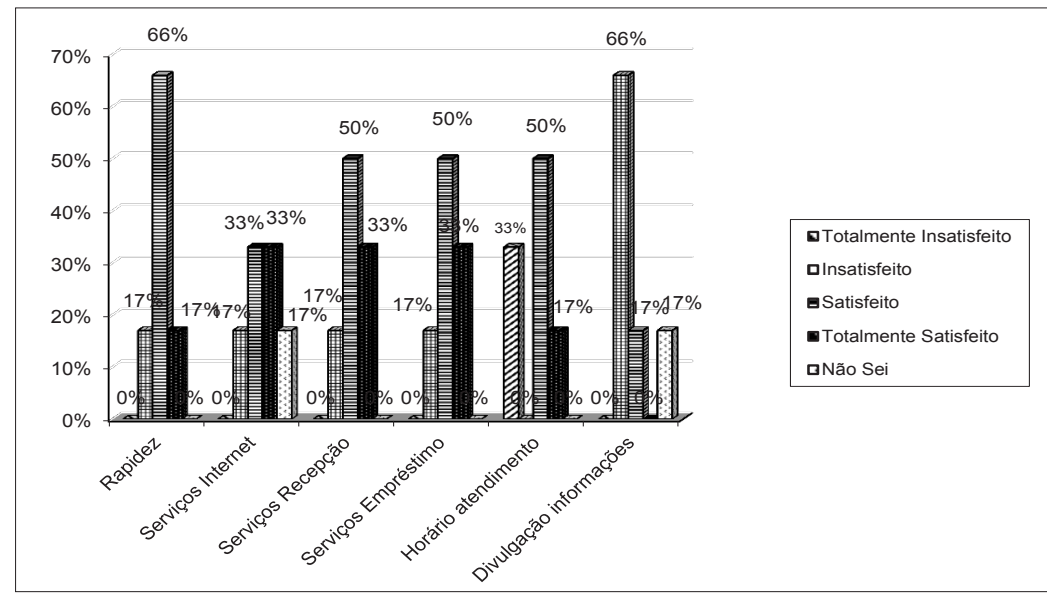

Para os professores os níveis de satisfação variaram entre $66 \%$ a $17 \%$ entre as variáveis. Rapidez atingiu o maior índice de satisfação $(66 \%)$, demonstrando ainda haver em percentuais proporcionais $(17 \%)$ níveis de insatisfação e satisfação total. Serviços da Internet apresentaram níveis variados proporcionalmente predominando (33\%) totalmente satisfeito e satisfeito. Para serviços de recepção apesar de 50\% estarem satisfeitos e 33\% totalmente satisfeitos, ainda há um percentual de 17\% insatisfeitos. Em relação ao horário de atendimento destacou-se $33 \%$ totalmente insatisfeitos. O item divulgação das informações atingiu o maior percentual $(66 \%)$ de insatisfação pelos docentes.

As variáveis parecem dividir as opiniões dos professores, identificando-se em âmbito geral que as variáveis horário de atendimento e divulgação das informações ainda não satisfazem da categoria de professores.

Gráfico 6 - Atendimento da Biblioteca - grau de satisfação dos servidores

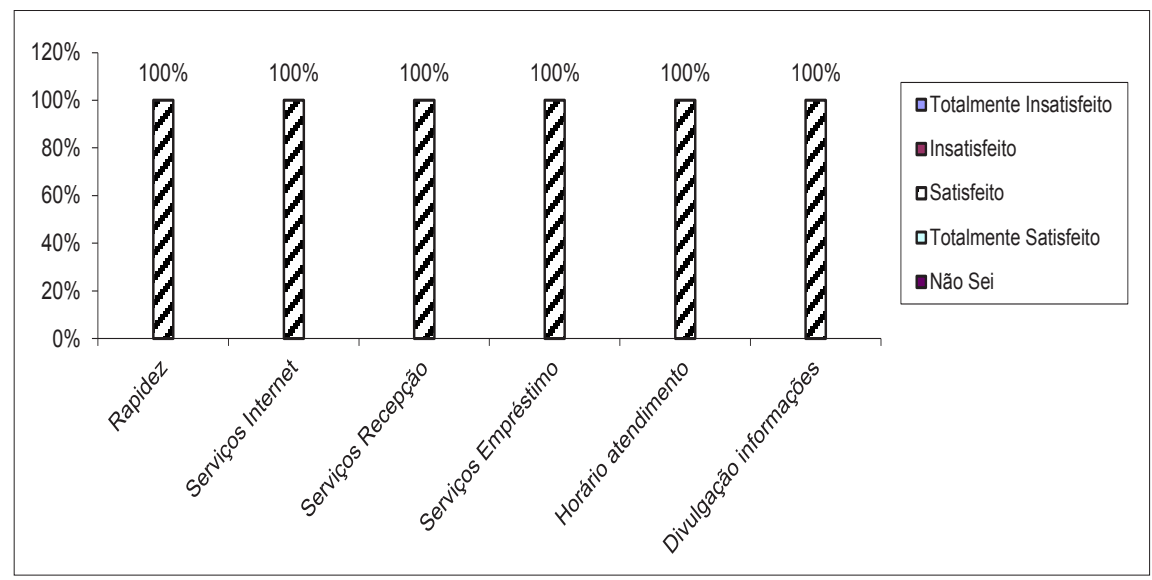

Em todas as variáveis analisadas em relação ao atendimento a categoria servidores encontra-se satisfeita, demonstrando um equilíbrio no nível de satisfação por este segmento usuário da Biblioteca.

\section{Acervo da Biblioteca}

Para análise do acervo da Biblioteca foram consideradas as seguintes variáveis: organização, acervo de referência, acervo de livros e acervo de periódicos.

O grau de satisfação dos usuários dos segmentos estudados estão demonstrados nos gráficos 7 a 9. 
Gráfico 7 - Organização do acervo - grau de satisfação dos alunos de graduação

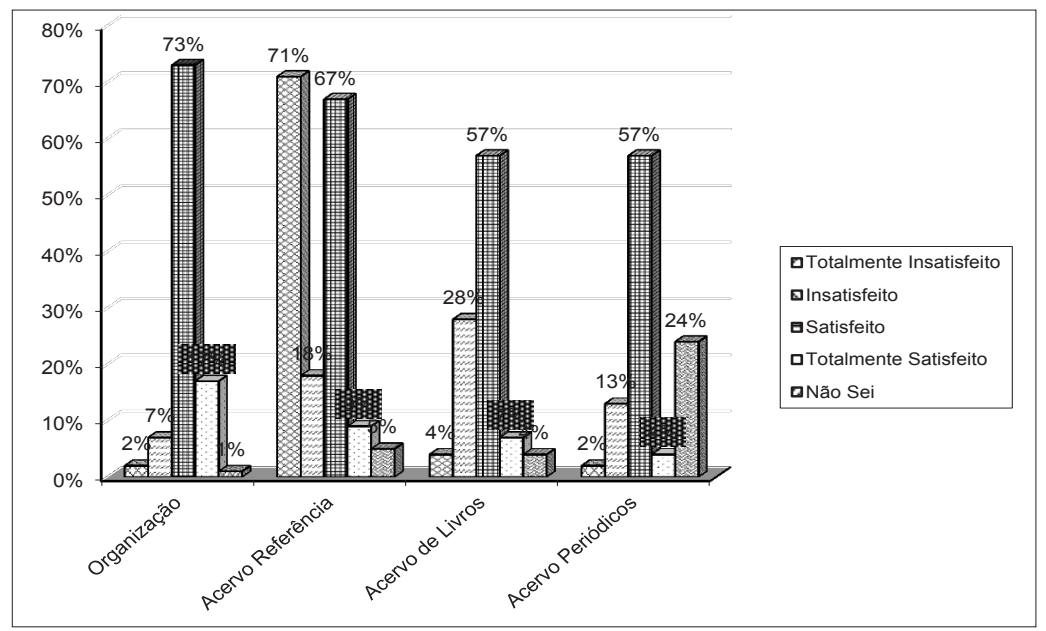

$\mathrm{Na}$ análise do item organização do acervo os níveis de satisfação atingiram todos os níveis de satisfação predominando principalmente o nível satisfeito (73\% a 57\%) em todas as variáveis investigadas. Em relação à organização os níveis de satisfeito e totalmente satisfeito atingiram os maiores percentuais respectivamente $(73 \%$ e $57 \%)$. Um pequeno percentual de $7 \%$ encontra-se insatisfeito e $2 \%$ dos alunos de graduação estão totalmente insatisfeitos. O acervo de referencia atinge o nível de totalmente insatisfeito e satisfeito para $71 \%$ e $67 \%$ dos alunos de graduação com percentuais menores entre $18 \%, 9 \%$ e $5 \%$ de insatisfação, total insatisfação e não sabe. Em relação aos acervos de livros e periódicos $57 \%$ dos alunos encontram-se satisfeitos, destacando-se para a segunda variável $24 \%$ que não souberam estabelecer um grau de satisfação.

Gráfico 8 - Organização do acervo - grau de satisfação dos professores

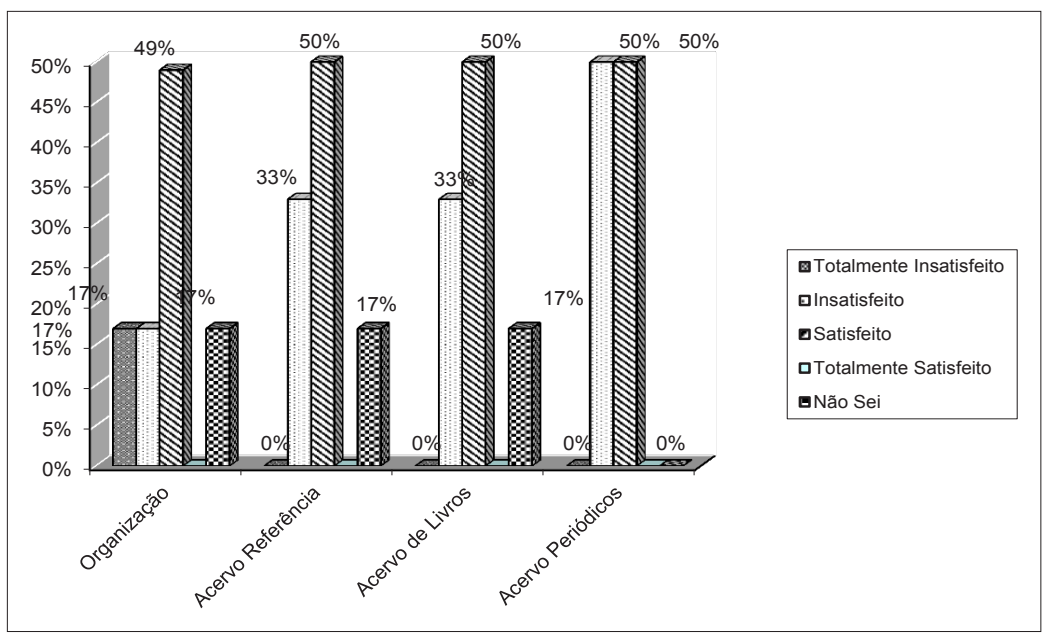

Para os professores o nível de satisfeito se distribuiu proporcionalmente em todas as variáveis ( $49 \%$ e $50 \%$ ), porém quase que equilibrou-se com o nível insatisfeito que variou entre $50 \%$ e $17 \%$. Demonstraram uma divisão na categoria professores o nível de satisfação. Para a variável organização os níveis variaram destacando-se primeiramente a satisfação (49\%) e empataram nível insatisfeito e totalmente insatisfeito e não conhecimento (17\%). Para as variáveis acervo de referência e acervo de livros, embora predomine a satisfação para $50 \%$ dos professores, $33 \%$ encontram-se insatisfeitos e ainda $17 \%$ estabeleceram um índice de satisfação. E para a variável acervo de periódicos equilibradamente $50 \%$ encontram-se satisfeitos contra outros $50 \%$ insatisfeitos. 
Gráfico 9 - Organização do acervo - grau de satisfação dos servidores

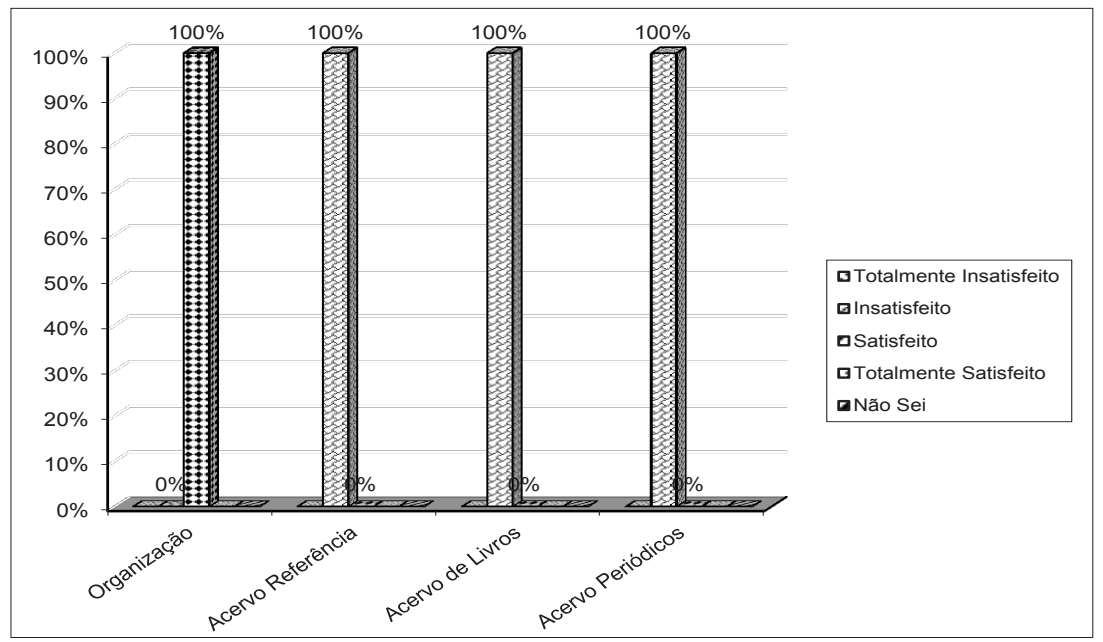

Para a categoria servidores a variável organização atinge o nível satisfação e as variáveis relacionadas à acervo foram consideradas dentro do nível de insatisfação.

\section{Servidores da Biblioteca}

Para análise dos servidores da Biblioteca foram consideradas as seguintes variáveis: disponibilidade, cortesia e disposição.

O grau de satisfação dos usuários, dos segmentos estudados, estão demonstrados nos gráficos 10 a 12.

Gráfico 10 - Servidores da Biblioteca - grau de satisfação dos alunos de graduação

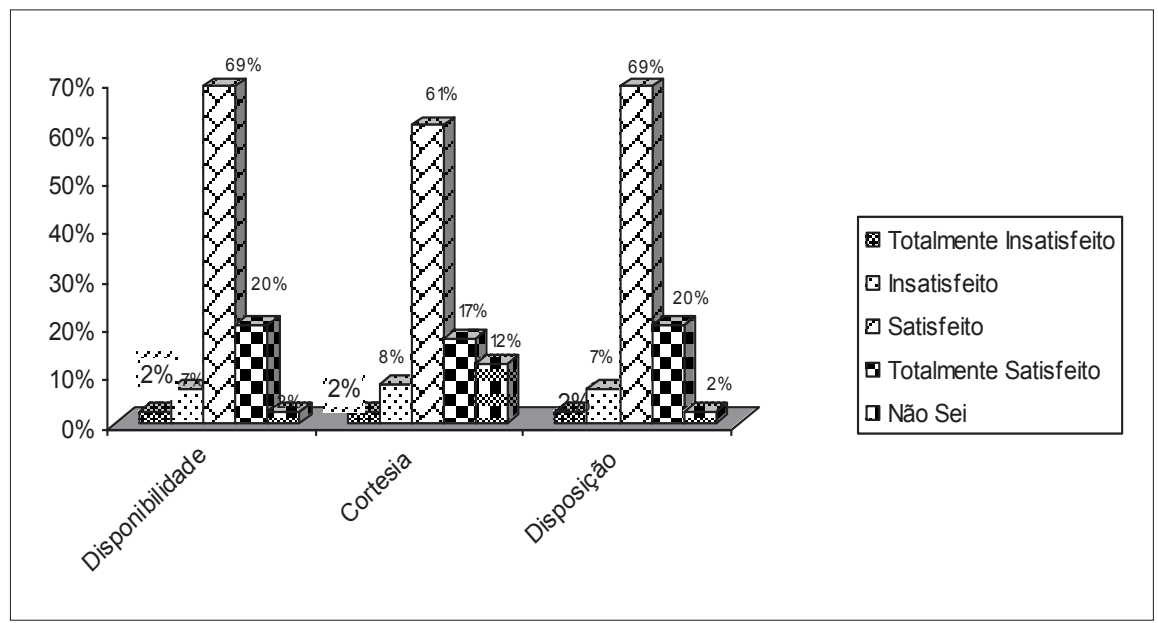


Os alunos da graduação encontram-se, em sua maioria, satisfeitos com os servidores da Biblioteca atingindo percentuais entre $69 \%$ e $61 \%$ em relação às três variáveis analisadas. Embora em percentuais menores que variaram entre $20 \%$ e $27 \%$ os alunos encontram-se totalmente satisfeitos e em menores percentuais ( $8 \%$ e $7 \%$ ) insatisfeitos. E ainda uma pe- quena parcela não saiba estabelecer um índice para cortesia, um pequeno percentual de $2 \%$ encontra-se totalmente insatisfeito.

Em um âmbito geral tanto a disponibilidade, quanto a cortesia e disposição dos servidores da Biblioteca atingiram bons graus de satisfação em relação à opinião dos alunos de graduação.

Gráfico 11 - Servidores da Biblioteca - grau de satisfação dos professores

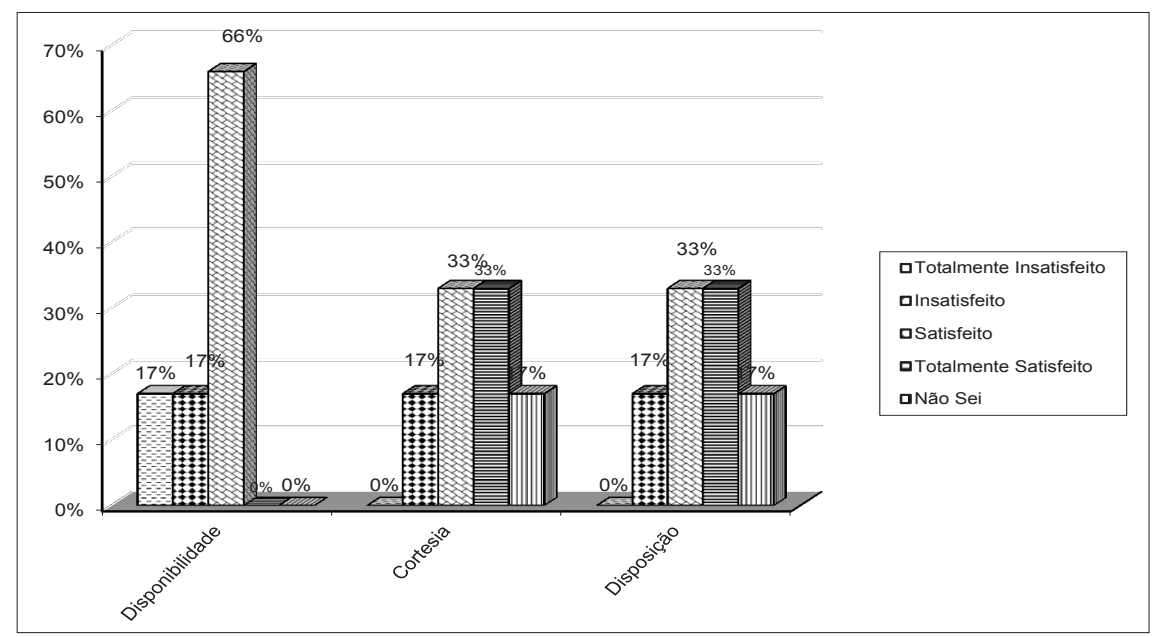

Para a categoria professores, há uma distribuição mais diversificada entre a variável disponibilidade em relação à cortesia e disposição.

Para disponibilidade $66 \%$ encontram-se satisfeitos, contra $17 \%$ que se dividem entre insatisfeitos e totalmente insatisfeitos. Para a cortesia e disposição os índices distribuem-se proporcionalmente entre satisfeito e totalmente satisfeito (33\%), enquanto $17 \%$ encontra-se insatisfeito e $17 \%$ não souberam estabelecer um índice de satisfação.

Gráfico 12 - Servidores da Biblioteca - grau de satisfação dos servidores

$100 \%$
$90 \%$
$80 \%$
$70 \%$
$60 \%$
$50 \%$
$40 \%$
$30 \%$
$20 \%$
$10 \%$
$0 \%$


Para os servidores, em percentuais unânimes todas as variáveis atingiram o índice de satisfeito.

\section{Discussão}

Tratando-se do espaço físico cabe destacar que o local utilizado hoje pela Biblioteca é adaptado onde há falhas e deficiências a serem melhoradas. Em relação à adequação dos espaços e estrutura geral ainda há um consenso bom de satisfação dos usuários, porém referindo-se às salas de estudo era de se esperar haver graus de insatisfação, uma vez que não há salas de estudo individual e poucas salas de estudo em grupo. Mesmo assim, para a categoria alunos de graduação o nível de satisfação é melhor do que para os professores e servidores.

Para a variável atendimento ao público houve uma variação grande nos níveis de satisfação ficando evidente que a insatisfação ocorre principalmente em relação às variáveis serviços da internet e divulgação das informações. Observa-se também, insatisfação em relação ao horário de atendimento principalmente pela categoria professores, apesar da Biblioteca prestar um atendimento de 13 horas por dia abrindo das 8 às 12 e das 13 às 22 horas de segunda a sexta-feira e aos sábados da 13 às 17 horas e já existir o projeto de abertura no horário de almoço.

Para as variáveis rapidez, serviços de recepção e de empréstimo o nível de satisfação os usuários foram mais favoráveis, podendo-se considerar que são nessas atividades que ocorre a interação entre servidor e usuário.

Para a variável acervo da Biblioteca de um modo geral para os alunos da graduação os índices de satisfação são favoráveis tanto em relação a organização e acervos. Destaca-se no entanto o acervo de referência que atingiu um índice de insatisfação quase proporcional ao nível de satisfação, cabendo aqui talvez maiores esclarecimentos a respeito deste segmento do acervo. Já para a categoria professores o acervo atinge índices quase proporcionais de satisfação e insatisfação, dividindo a categoria entre esses dois níveis. Cabe destacar aqui a insatisfação em relação ao acervo de periódicos para essa categoria. $\mathrm{Na}$ categoria servidores a organização atinge índice de satisfação e em relação ao acervo insatisfação, divergindo aqui a opinião deste segmento.

Quanto aos servidores da Biblioteca a maioria dos alunos de graduação encontra-se satisfeita com os mesmos em todas as variáveis de disponibilidade, cortesia e disposição.

Para o segmento professores há divergências em relação à disponibilidade, que é satisfatória, contra a cortesia e disposição que se equilibra entre satisfação e insatisfação. Para os servidores há a concordância de satisfação para as três variáveis investigadas.

Considerando que as três categorias de usuários investigadas são segmentos distintos da comunidade universitária e apresentam números de representatividade e freqüência diferenciados os resultados a serem obtidos apresentariam opiniões e níveis de satisfação diferenciados.

\section{Considerações Finais}

Pelas respostas obtidas pode-se concluir que há pontos a serem reavaliados e indicações a serem analisadas buscando melhorias e adequações para atingir um melhor índice de satisfação dos usuários investigados tais como:

- Estudo de melhorias no espaço físico da Biblioteca, principalmente em relação às salas de estudo em grupo;

- Analisar os serviços prestados via Internet buscando criar mais interatividade em atendimento virtual;

- Ampliar o horário de atendimento da Biblioteca, principalmente atendendo o horário de almoço.

- Melhorar a forma de divulgação das informações sobre a Biblioteca, buscando divulgar mais os serviços prestados e criar uma maior interatividade entre Biblioteca e Comunidade universitária.

- Promover mais divulgação e esclarecimentos sobre os acervos, principalmente no tocante ao acervo de referência e periódicos, buscando divulgar a finalidade do acervo de referência e as fontes disponíveis no acervo de periódicos, principalmente sobre o Portal de Periódicos da CAPES que a Biblioteca tem acesso.

- Realizar estudos pontuais para identificar as reais causas da insatisfação dos servidores em relação ao acervo da Biblioteca.

- Ampliar o quadro de servidores da Biblioteca visando aumentar a disponibilidade de servidores para atendimento na Biblioteca, promover treina- 
mentos e investir no relacionamento interpessoal e técnicas de atendimento ao público buscando melhorar os níveis de cortesia e disposição dos servidores que prestam serviços na Biblioteca.

- Cabe ainda realização de estudos pontuais em relação às variáveis que atingiram índices de insatisfação buscando identificar e/ou detectar os reais pontos falhos que podem ser melhorados buscando atender as necessidades da comunidade universitária;

- Investir em estratégias de marketing da Biblioteca visando divulgar e atender as necessidades dos clientes da Biblioteca.

\section{Referências}

BAPTISTA, M. M. ; LEONARDT, M. P. L. A qualidade dos serviços prestados e a satisfação dos usuários em uma Biblioteca Universitária. Bibl. Univ., Belo Horizonte, v. 1, n.1, p. 50-59, jan./jun. 2011.

BAPTISTA, S. G.; CUNHA, M.B. Estudo de usuários: visão global dos métodos de coleta de dados. Perspectivas em Ciência da Informação, v. 12, n. 2, p. 168-184, maio/ ago. 2007. Disponível em: http://www.scielo.br/pdf/pci/ v12n2/v12n2a11.pdf. Acesso em: 20 nov. 2011.

GROGAN, D. A prática do serviço de referência. Brasília: Briquet de Lemos/Livros, 1995. Cap. 5- Buscas. p. 109-152.

GUIMARÃES, J. A. Moderno profissional da informação: elementos para a sua formação e atuação no Mercosul com vistas ao terceiro milênio. ENCUENTRO DE DIRECTORES, 3 Y DOCENTES DE LAS ESCUELAS DE BIBLIOTECOLOGIA DEL MERCOSUR, 2 (Santiago (Chile): 1998). Anais... Santiago (Chile): Universidad Tecnológica Metropolitana, 1998.

LANCASTER, F. W. Avaliação de serviços de bibliotecas. Tradução de Antonio Agenor Briquet de Lemos. Brasília. Briquet de Lemos, 1966.

OLIVEIRA, A. M. et. al. Gerenciamento do capital humano em bibliotecas ou centros de informação: desafio importante pela sociedade do conhecimento. Transformação, v./ 12 n./2, p.7-16, jul./dez./2000.

OLIVEIRA NETO, José Dutra de; RICCIO, E L. Desenvolvimento de um instrumento para mensurar a satisfação do usuário de sistemas de informação através do método survey. Disponível em: <http://www.tecsi.fea. usp.br/riccio/tac/pdf/art-menssurvey.pdf>. Acesso em 12 fev. 2012.

PEREIRA, A. S.; SCHMIDT, A. S.; GODOY, L. P. et al. Satisfação dos usuarios de uma biblioteca universitária segundo as dimensões da qualidade. Disponível em: $<$ http://www.simpep.feb.unesp.br/anais/anais_13/ artigos/120.pdf $>$. Acesso em 14 fev. 2012.

PINHEIRO, M. I. S.; GODOY, L. P. Qualidade em serviços: uma análise da satisfação dos usuários em bibliotecas universitárias. In: ENCONTRO NACIONAL DE ENGENHARIA DE PRODUÇÃO, 22, 2002. Curitiba: ENEGEP, 2002. Disponível em: <http://www.abepro.org. br/biblioteca/ ENEGEP2002_TR261325. pdf >. Acesso em: 20 nov. 2011.

PRADO, Heloisa de Almeida. Organização e administração de bibliotecas. 2. ed. rev. São Paulo: T. A. Queiroz, 2003.

RABELLO, M. A. F. R. Avaliação da qualidade dos produtos/serviços da informação: uma experiência da Biblioteca do Hospital Universitário da Universidade de São Paulo. Revista Digital de Biblioteconomia e Ciência da Informação, Campinas, v. 2, n.1, p. 80-100, jul./dez. 2004. Disponível em: <http://www.sbu.unicamp.br/seer/ojs/index. php/sbu_rci/article/viewFile/304/183>. Acesso em: 20 nov. 2011.

RAMOS, M. E. M. org. Tecnologia e novas formas de gestão em bibliotecas universitárias. Ponta Grossa, UEPG, 1999. 257p.

ROTHSTEIN, S. The developement of reference services through academic traditions, public library practice and especial librarianship. (ACRL monographs, 14). Cap. 2 The genesis of reference seivice: 1875-1895.

SCHWITZER, Fernanda. Os novos perfis dos profissionais da informação nas bibliotecas universitárias. Revista Brasileira de Biblioteconomia e Documentação, Nova Série, São Paulo, v. 3, n. 2, p. 80 - 88, jul./dez. 2007.

SILVA, L. N. Líder sábio: novo perfil de liderança do terceiro Milênio. Rio de Janeiro: Record, 1998.

SILVEIRA, F. X. da; QUINTANA, I. M.; FEIJÓ, S. R. Pesquisa de satisfação e perfil do usuário: Biblioteca Clóvis Vergara Marques. Disponível em: <http://www.poa.ifrs. edu.br/wp-content/uploads/2011/09/Artigo_PESQUISADE-SATISFA $\%$ C3\%87\%C3\%83O.pdf $>$. Acesso em: 14 fev. 2012.

TARAPANOFF, K. Perfil do profissional da informação no Brasil: diagnóstico de necessidades de treinamento e educação continuada. Brasília: IELDF Ed., 1997. 136p.

Data de Submissão: outubro de 2012

Data de aprovação: abril de 2013 